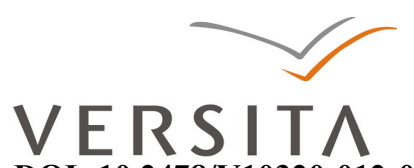

DOI: $10.2478 /$ V10320-012-0042-5

\title{
THE ROLE OF GENDER IN VERBAL DISAGREEMENT: A STUDY OF DISAGREEMENT STRATEGIES EMPLOYED BY HUNGARIAN UNDERGRADUATE STUDENTS
}

\author{
HELGA VANDA KOCZOGH \\ University of Debrecen, \\ 4032 Debrecen, Egyetem tér 1, Hungary \\ koczoghh@gmail.com
}

\begin{abstract}
The aim of the paper is to present the results of a study on the interplay of gender and disagreement strategies employed by Hungarian undergraduate students. The data for analysis is a corpus of oral face-to-face dyadic interactions; the methodology makes use of both qualitative and quantitative tools and involves identifying disagreement strategies on the basis of previous research as well as patterns emerging from the corpus. The results of the study contradict previous claims that in comparison to men, women disagree less frequently and, when they do disagree, they employ less direct strategies.
\end{abstract}

Keywords: disagreement strategies, gender differences, Hungarian, im/politeness, sociopragmatics

\section{Introduction}

In the past few decades, there has been an increasing interest in conflict talk in several different fields, e.g. psychology, philosophy, sociology, and linguistics. Despite an extensive body of research into conflict in the social sciences in comparison to conflict talk, the study of disagreement per se within conflict episodes and its features is relatively recent. In linguistics, disagreement has been investigated within the frameworks of speech act theory (Sornig 1977), politeness theory (Holtgraves 1997), conversational analysis (Kotthoff 1993; Pomerantz 1984; Sacks 1987), discourse analysis (Georgakopoulou 2001; Kakavá 1995; Schiffrin 1985), relevance theory (Locher 2004), and even social psychological pragmatics (Muntigl and Turnbull 1998). The growing popularity of disagreement as a research subject among linguists can be attributed to the 
following factors: disagreement is one of the most commonly occurring speech events in everyday interactions; it has a complex nature; and it raises the widely-researched issues of im/politeness and in/appropriateness.

Another area of research which has received increasing attention over the past 40 years is the interplay of language and gender. Robin Lakoff's (1975) pioneering book, Language and Woman's Place, inspired innumerable studies seeking to disentangle the complex interaction between gender and communication by examining the linguistic practices of men and women.

While numerous studies have been undertaken in the two above-mentioned fields separately, so far there has been limited research on the relationship between gender and disagreements. Furthermore, these studies tend to focus on one gender exclusively and they predominantly investigate the linguistic manifestation of disagreement, ignoring its functional spectrum. Moreover, to my best knowledge, research to date on disagreement has not been carried out in Hungarian.

Hence, there remains a need to remedy these gaps observed in the literature. The aim of my paper is, thus, twofold: (1) to identify the disagreement strategies employed by Hungarian undergraduate students and (2) to examine the effect of the gender of the speaker on the expression of verbal disagreement both in terms of frequency of use and the particular strategies utilized.

\section{Theoretical foundations}

\subsection{Defining disagreement}

There has been a great deal of variation in the literature in the way in which the term disagreement has been used (cf. Koczogh 2011). In my definition verbal disagreement is a speech act expressing the speaker's opinion or belief, whose illocutionary force is partly or fully inconsistent with that of the previous speaker's utterance. It is important to note two things here:

(1) Disagreement is interpreted here as a speech act, so the truth value of the first speaker's (S1) utterance and that of the second speaker's utterance (S2) do not have to be in contrast with each other. This point is illustrated by Example 1 (disagreement is indicated by an arrow): 


\section{Example 1}

Two tourists are talking about S2's itinerary:

S1 So, are you going to visit The Big Apple tomorrow?

$\rightarrow \quad$ S2 No, I'm going to New York City.

S2's utterance is defined as an act of disagreement, even though the propositional contents of the two utterances are not opposite to each other, since S2 lacks the world knowledge that The Big Apple is a nickname for New York City and believes that they are talking about two different entities.

(2) Analysing the speaker's belief is always problematic, as it is hard or in some cases even impossible to access. S2's utterance, however, does not always have to mirror the speaker's belief, as it can be a joke or teasing and still count as an act of disagreement. For instance, in Example 2, the illocutionary force of S2's utterance is disagreement with S1's boasting about his looks, which is expressed by a joke. Naturally, S2 does not think that S1 has a star-like head.

\section{Example 2}

S1 No wonder that every girl in class is into me: I have a baby face and star-like eyes.

$\rightarrow \quad$ S2 Star-like is your head!

From now on disagreement is going to be identified and analysed based on the definition above, bearing in mind the two aforementioned points.

\subsection{Previous studies on gender and disagreement.}

As mentioned in the Introduction, there is limited research available on the relationship of gender and disagreements. Although gender is not in the scope of many studies on conflict talk, some of them do reflect on the influence of gender in the results. I now turn to the overview of these relevant studies in the field of gender and disagreement.

Over the last three decades, a considerable number of studies have suggested that women have a greater tendency to seek agreement and avoid explicit disagreement both in single-sex and mixed-sex settings than men do (Edelsky 1981; Coates 1989; Tannen 
1990). Research on gender differences in conversational style has yielded results that women are more likely than men to soften their disagreements, while men tend to challenge and dispute the utterances of their conversational partner in a direct way.

Pilkington's (1992) study on same-sex groups of workers in a New Zealand bakery provides further evidence of this pattern. The women in the study used a highly cooperative conversational style with a lot of agreement, and positive minimal feedback and they frequently finished each other's utterances. The men, on the other hand, repeatedly challenged each other and disagreed bluntly. Another feature that characterized the male data was the occurrence of direct expression of hostility via open criticism and insults.

Similar gender-related patterns have been found in other contexts as well. Investigating the expression of agreement and disagreement in educational online discussion groups, Guiller and Durndell (2006) found that female postings were more likely to include agreement while male postings tended to include challenges and disagreement. Women's disagreeing utterances were rarely aggravated and were often attenuated through the use of "(I think) I'll have to". Intensified and personalised forms of agreement (such as "I agree completely", "I totally agree with you") proved to be a solely female feature. Men, on the other hand, were significantly more likely to disagree explicitly than women and they used controversial and challenging statements more frequently. No significant gender difference was found in the use of partial agreement (such as "Yes, but...").

Nevertheless, not all studies report findings consistent with the previous ones. Rees-Miller (2000:1106), for instance, examining the expression of disagreement in academic setting did not find gender an influential factor in either the rate of disagreement or the use of softeners of disagreement. However, her findings suggest that men are more likely to use aggravated disagreements than women. 


\section{Data and methodology}

\subsection{Corpus and participants.}

The present paper attempts to fill the gaps observed in the relevant literature by analysing verbal disagreement in mixed-sex dyadic face-to-face encounters of Hungarian undergraduate students within a task-based framework employing a combined qualitative and quantitative approach to data analysis. The corpus compiled for analysis consists of 68,193 words, which is approximately 444 minutes (7hrs 24mins) of task-based speech (recorded by myself between December 2009 and March 2010).

The participants ( 15 men, 15 women, $\mathrm{M}_{\mathrm{age}}=20.4$ years, age range: $18-24$ years) of the study comprised a homogenous group as they were all of similar age and of similar education (they had all passed a high school maturation exam). The relationships between the participants were at the two ends of the social distance continuum, i.e. they either had very strong ties (siblings or couples who had been dating each other for at least a year; $\mathrm{n}=12)$ or were strangers $(\mathrm{n}=18)$ (for further details on the corpus, participants, and data elicitation see Koczogh 2011).

\subsection{Methodology}

After transcribing the recordings, the scripts were searched for instances of disagreement. Altogether 525 tokens of disagreement were identified in the corpus, which were then manually indexed according to their function. The categories used were based on the functions of disagreement described in previous research (e.g. Culpeper 2011; Locher 2004; Muntigl and Turnbull 1998; Rees-Miller 1995, 2000) as well as on new ones (e.g. implied contradiction, clarification of speaker's meaning, disbelief), identified on the basis of the patterns found in the corpus.

Based on their function, disagreements were assigned to one of the categories listed below. Due to space limitations, these disagreement strategies are only briefly defined and only those which have not been identified in previous literature are illustrated by an example. The abbreviations of the categories used for indexing are shown in brackets.

- $\quad$ artial agreement/token agreement (P/TA): partial agreement is an utterance that makes a concession before expressing opposition in order to soften 
the force of disagreement. Token agreement is a polite disagreement disguised as an agreement.

- $\quad$ explanation (give/ask for reason/example) (EXPL): an utterance that gives or asks for a reason or example to indicate that the previous speaker's proposition is not true. When asking for a reason, the speaker's interrogation is usually accompanied by a critical or doubtful tone.

- $\quad$ contradictory statement (CST): an utterance that expresses contradiction by either negating the proposition expressed by the previous claim or directly stating that it is not true.

- $\quad$ implied contradiction (IC): an utterance that, by itself, "does not bear any markers of disagreement. However, in the context in which it occurs, it contradicts a previous utterance" (Rees-Miller, 1995:116).

\section{Example 3}

Discussion on gender differences in cooking skills

S1 Főzési tudományom a tojásrántottában ki is merül.

My knowledge of cooking ends with scrambled eggs.

S2 De abba teszel jó sok mindent, igaz?

But you put a lot of things in it, right?

$\rightarrow \quad$ S1Tojást.

Eggs.

- $\quad$ stating disagreement (STD): an utterance that explicitly states that the speaker disagrees with the previous proposition.

- $\quad$ challenge $(\mathrm{CH})$ : an utterance that displays strong disagreement with the prior proposition by questioning the addressee's position and implicating that (s)he cannot provide evidence for his/her claim. It typically has the syntactic form of interrogative or imperative.

- $\quad$ disbelief (DISB): an utterance that expresses that the speaker does not believe or doubts the previous proposition and does not hold it to be true.

\section{Example 4}

Discussion about a character of a story 
S1 [De] hát most ő mit tehet arról? \{hogy balf***\}

[But] what does he have to do with it? \{that he is a dumbf***\}

S2 M: olvasni kellett volna a sorok között.

$\mathrm{U}: \mathrm{hm}$ he should have read between the lines.

$\rightarrow \quad$ S1 Jaj, UGYAN MÁ:R!

Oh, COME O:N!

- $\quad$ evaluation (EVA): an utterance that expresses a negative evaluation of the previous speaker's proposition, indicating strong disapproval.

- $\quad$ clarification of speaker's meaning (C'SM): an utterance that clarifies the usually misunderstood meaning of the speaker's previous utterance, which, therefore, contradicts or corrects the other interlocutor's previous proposition.

\section{Example 5}

Discussion about euthanasia

S1 De én azt mondom, hogy ehhez egy nagy adag pesszimista

világnézet is kell. Le kell tojni önmagunkat néha ahhoz, hogy ö: ... hogy hogy ilyen ilyen estekben hogy úgymond 'meg akarok halni, mert izé ronda vagyok, meg itt a púp a hátamon'. (irónikus)

But I say that for this you need a great deal of pessimistic worldview. Sometimes we need to get over ourselves so that $u: h$... that that in such such cases like "I want to die because I'm ugly and there is a hunch on my back". (ironical)

$\rightarrow \quad$ S2 De nem úgy Maci, én nem erről beszélek.

But it's not that, Honey Bear, I'm not talking about that.

\section{Data analysis and results}

In order to analyse the data both descriptive and inferential statistics were used. Descriptive statistics measured the frequency of disagreements based on gender and it was also used to calculate the ratio of the disagreement strategies employed. Given the nature of the data, the study also employed the Chi-square test to investigate whether the associations between gender and the use of disagreement strategies are statistically significant. The results of the statistical procedures are presented below.

\subsection{Gender and frequency of disagreements}


Disagreement in my research was expressed either via a single disagreement strategy $(67.05 \%)$ or optionally with a combination of two $(32.57 \%)$ or sometimes even three strategies $(0.38 \%) .34(6.49 \%)$ tokens were unfinished, still they managed to deliver opposition and their function could also be identified.

As for the influence of the gender of the speaker on the rate of disagreements, the descriptive statistical analysis reveals that out of the 525 tokens of verbal disagreement that occur in the corpus, $302(57.52 \%)$ were uttered by women while $223(42.48 \%)$ by men. The gap in the ratio of disagreements used by male and female undergraduates is further broadened if we take into account the fact that men spoke more than women did. Out of 68,194 words 36,877 (54.08\%) were uttered by the former and 31,317 (45.92\%) by the latter. Figure 1 displays the relative proportion of disagreements and the uttered words in percentages in relation to gender.

Figure 1

Gender differences in the proportion of disagreements and uttered words in percentage

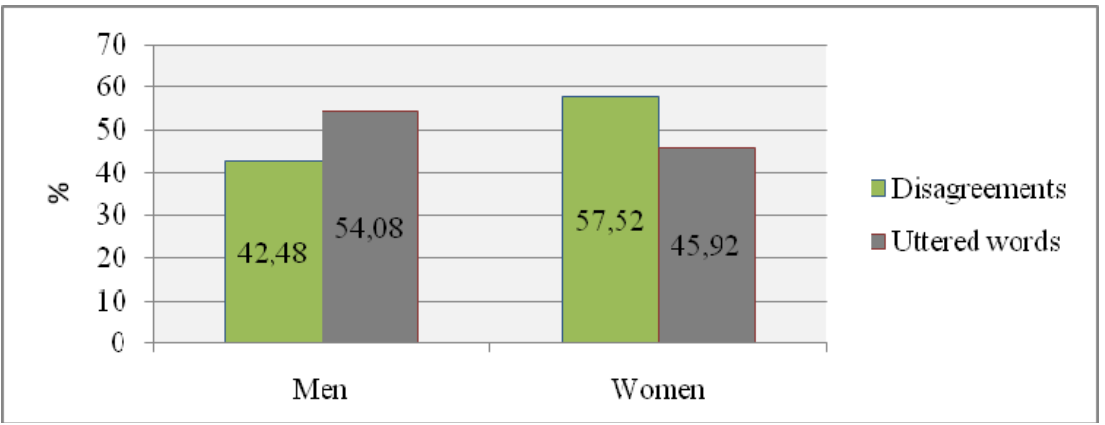

It can be observed that in my sample the number of disagreements is inversely proportional to the uttered words, i.e. the number of disagreements increases as the amount of talk decreases. The graphical representation of this pattern resembles the Roman letter "X".

A clearer picture of the ratio of disagreements used by male and female speakers can be drawn by calculating the frequency of disagreements per 100 words. The obtained results show that men employed 0.6 token of disagreement per 100 words, while women expressed opposition in almost every 100 word (0.96 token/100 words). This demonstrates that the female speakers in my research expressed disagreement much more 
frequently than their male counterparts. Thus, previous claims on women expressing their disagreement less frequently than men do were not substantiated by the findings.

It is noteworthy that individual differences can be observed in terms of the frequency of disagreements, which might be due to, among other things, different personality traits and/or communicative styles.

\subsection{Gender and disagreement strategies}

In order to explore the association between the gender of the speaker and the overall distribution of disagreement strategies adopted by the participants descriptive statistics were used. As already discussed, women have generally been reported to be more indirect than men (Lakoff 1975; Pilkington 1992; Tannen 1990). Hence, in the current study, female speakers were predicted to employ proportionally more indirect and less direct disagreement strategies than male speakers do.

The overall distribution of single and combined disagreement strategies by gender is represented graphically in Figure 2. It is apparent that men adopted the strategies of contradictory statement $(27.08 \%)$, explanation $(10.3 \%)$ and disbelief $(8.1 \%)$ the most frequently as a single disagreement strategy, while women were in favour of contradictory statement (30.1\%), disbelief $(8.6 \%)$ and partial agreement/token agreement $(8 \%)$. Some discrepancies can be observed in the use of certain strategies in terms of their frequency in the male and in the female corpus.

Figure 2

Overall distribution of disagreement strategies by gender

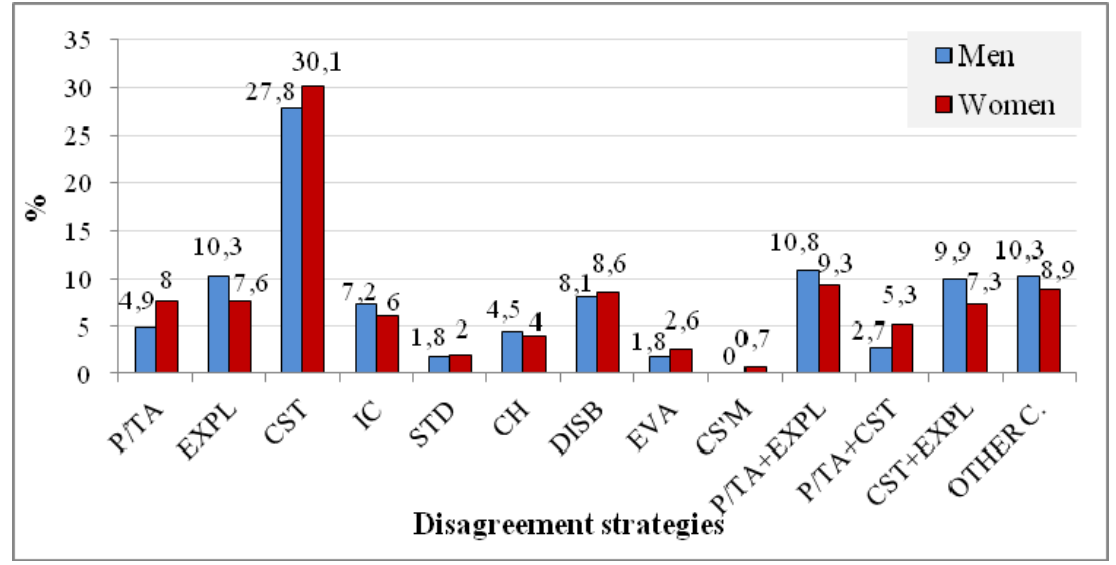


For instance, when compared to men, women utilized significantly more partial/token agreement ( $8 \%$ versus $4.9 \%)$ and evaluation $(2.6 \%$ versus $1.8 \%)$ and they accounted for all the instances of clarification of speaker's meaning $(0.7 \%)$. The fact that men in this study were not observed to use the last function should not be taken to mean that in general men never use this disagreement strategy. This finding needs to be substantiated by further research that investigates disagreements expressed by men and women using a larger sample of speech.

As regards the combinations of disagreement strategies, the following patterns can be observed: men used slightly more partial agreement followed by an explanation $(10.8 \%$ versus $9.3 \%)$ and more contradictory statement followed by an explanation $(9.9 \%$ versus $7.3 \%$ ). Women, on the other hand, employed the combination of contradictory statement preceded by partial agreement (5.3\% versus $2.7 \%)$ significantly more frequently than men did.

Figure 2 indicates that although both men and women utilized explicit and implicit disagreement strategies, women in this study tended to adopt more direct strategies (e.g. contradictory statement, evaluation) than men did. Thus, it implies that women might have a more assertive communication style than has been reported in previous literature.

Although the overall distribution of disagreement strategies used by men and women shows some significant differences, the result of the Chi-square test indicates that the association between gender and the use of disagreement strategies is not statistically significant $(\mathrm{p}=.782)$.

\section{Conclusion}

The aim of the present paper was to study the effect of gender on the frequency of disagreements and the particular disagreement strategies employed by Hungarian undergraduate students. On the basis of the empirical results it can be concluded that contrary to expectations, female Hungarian undergraduates do express opposition frequently. Women participating in this study tended to disagree much more frequently and often in a more expressive and straightforward way than men did. These results 
refute previous findings on the communication style of women and imply that the female speakers of this study were willing to sacrifice attending the other's face for the sake of efficiency of communication or preservation of one's own face. Inevitably, as a result of the relatively small sample size, the findings are not representative of a broader university community, cannot be generalized and need to be substantiated by further research.

Acknowledgement: The research reported here is supported, in part, by OTKA (Hungarian Scientific Research Fund), grant number: K 72983; by the TÁMOP-4.2.1/B09/1/KONV-2010-0007 project, which is implemented through the New Hungary Development Plan co-financed by the European Social Fund and the European Regional Development Fund; and by the TÁMOP-4.2.2/B-10/1-2010-0024 project, which is cofinanced by the European Union and the European Social Fund.

\section{References}

Coates, J. 1989. 'Gossip Revisited: Language in All-Female Groups' in J. Coates and D. Cameron (eds.). Women in their Speech Communities. London: Longman, pp.75-94.

Culpeper, J. 2011. Impoliteness: Using Language to Cause Offence. Cambridge: Cambridge University Press.

Edelsky, C. 1981. 'Who’s Got the Floor?' in Language in Society. 10 /3, pp.383-421.

Georgakopoulou, A. 2001. 'Arguing about the Future: on Indirect Disagreements in Conversations' in Journal of Pragmatics. 33, pp.1881-1900.

Guiller, J. and A. Durndell. 2006. "I totally agree with you': Gender Interactions in Educational Online Discussion Groups' in Journal of Computer Assisted Learning. 22, pp. 368-381.

Holtgraves, T. M. 1997. 'Yes, but...: Positive Politeness in Conversation Arguments' in Journal of Language and Social Psychology. 16, pp.222-239.

Kakavá, C. 1995. 'Directness and Indirectness in Professor-Student Interactions: The Intersection of Contextual and Cultural Constraints' in Georgetown University Round Table, pp.229-246.

Koczogh, H. V. 2011. 'Gender Differences in Disagreement Strategies Employed by Speakers of Hungarian' in California Linguistic Notes. 36/2 [Online]. Available: http://hss.fullerton.edu/linguistics/cln/Sp2011PDF/Koczogh-GenderDiff.pdf [2011, September 25].

Kotthoff, H. 1993. 'Disagrement and Concession in Disputes: on the Context Sensitivity of Preference Structures' in Language in Society. 22, pp.193-216.

Lakoff, R. 1975. 'Language and Women's Place' in Language and Society. 2, pp.45-80. 
Locher, M. 2004. Power and Politeness in Action: Disagreements in Oral Communication. Berlin: Mouton de Gruyter.

Muntigl, P. and W. Turnbull. 1998. 'Conversational Structure and Facework in Arguing' in Journal of Pragmatics. 29/3, pp.225-256.

Pilkington, J. 1992. ' Don’t try and make out that I'm nice!' The Different Strategies Women and Men Use when Gossiping' in Wellington Working Papers in Linguistics. 5, pp.37-60.

Pomerantz, A. 1984. 'Agreeing and Disagreeing with Assessments: Some Features of Preferred/Dispreferred Turn Shapes' in J. Atkinson and J. Heritage, (eds.). Structures of Social Action: Studies in Conversation Analysis. Cambridge: Cambridge University Press.

Rees-Miller, J. 1995. Linguistic Features of Disagreement in Face-to-Face Encounters in University Settings. Unpublished PhD thesis. SUNY at Stony Brook.

Rees-Miller, J. 2000. 'Power, Severity, and Context in Disagreement' in Journal of Pragmatics. 32, pp.1087-1111.

Sacks, H. 1987. 'On the Preferences for Agreement and Contiguity in Sequences in Conversation' in G. Button and J.R. Lee (eds.). Talk and Social Organisation. Clevedon: Multilingual Matters, pp.5469.

Schiffrin, D. 1985. 'Everyday Argument: The Organization of Diversity in Talk' in T. van Dijk (ed.). Handbook of Discourse Analysis: Discourse and Dialogue. London: Academic Press, pp.35-46.

Sornig, K. 1977. 'Disagreement and Contradiction as Communicative Acts' in Journal of Pragmatics. 1, pp.347-374.

Tannen, D. 1990. You Just Don't Understand: Women and Men in Conversation. New York: Ballantine Books. 